\title{
Standard of medical tribunal reports in a high secure setting
}

\author{
Paula Marie Murphy, Amlan Basu ${ }^{2}$
}

The Psychiatrist (2012), 36, 463-466, doi: 10.1192/pb.bp.112.038687

${ }^{1}$ South London and Maudsley rotation;

${ }^{2}$ Broadmoor Hospital, Crowthorne

Correspondence to Paula Marie

Murphy (paulamurphy2@nhs.net)

First received 21 Jan 2012, final revision 18 Apr 2012, accepted 13 June 2012
Aims and method To investigate whether medical tribunal reports were meeting acceptable standards as set out in the practice direction issued by the Tribunal Service in 2010. We looked at 50 medical reports and compared the content of the reports with a 13-item checklist that was derived from the recommendations set out in the practice direction.

Results The results show a number of areas where the reports are not meeting acceptable standards. For 5 of 13 items in our checklist, less than $80 \%$ of reports evaluated included the required information.

Clinical implications The results have important clinical governance implications. As clinicians we need to improve our report writing, not least because it is our professional and statutory duty but also to avoid potential repercussions from the tribunal in terms of their legal power to order remedies, sanctions and costs. Improvements might be achieved through robust performance management of individual clinicians and consideration being given to including this in revalidation procedures.

\section{Declaration of interest None.}

The tribunal is an independent judicial body that operates under the provisions of the Mental Health Act 1983 (as amended in 2007). ${ }^{1}$ Their main purpose is to review the cases of patients detained under the Mental Health Act and to direct the discharge of any patients where the statutory criteria for detention are not met. This involves making a balanced judgement on a number of issues such as the patient's diagnosis and the need for medical treatment, the freedom of the individual, the protection of the public and the best interests of the patient. ${ }^{1}$ The tribunal relies heavily on the written reports of involved professionals in making their decision on the appropriateness of continuing with the detention of the patient. For many years there was little guidance available to professionals in the preparation of reports for the tribunal. This was highlighted in 1997 by Davison \& Perez de Albeniz, 'little advice is offered in the literature for the novice report writer, despite the gravity of the situation'.2 They compiled a list of 'features to be included' in reports for mental health review tribunals and managers' reviews. Audit of reports before and after distribution of their list revealed an improvement in the quality of reports. Another study in 1998 by Ismail et al looked at the quality of medical reports for tribunals. ${ }^{3}$ In this study they assessed quality by looking at whether or not the reports stated the criteria for continuing detention, based on the detention under Section 3 of the Mental Health Act. They compared the standard of reports according to the seniority, qualifications and specialty of the doctor. They found that the majority of the reports were written by junior doctors and did not fulfil the criteria laid down by the Mental Health Act 1983. Consultant and forensic psychiatry status were associated with appropriately completed reports.

The first guidance available to clinicians on report writing for the mental health tribunal was in 2000 by the Regional Chairmen of the Mental Health Review Tribunal for England and Wales, ${ }^{4}$ which followed consultation with the Royal College of Psychiatrists. These guidelines consisted of 18 criteria. Following this, a study by Egleston $\&$ Hunter $^{5}$ in 2002 looked at the quality of reports before and after the implementation of the guidelines. They found that providing clinicians with this 18-item checklist improved the quality of the reports. They also reported a secondary benefit - that feedback from clinicians was that writing reports was quicker and easier when authors knew what was expected of them. The results of this study were replicated in an audit cycle in 2008 by O'Muirithe \& Shankar. ${ }^{6}$ On 3 April 2006 The Tribunals Service was created as an executive agency of the Ministry of Justice to provide administrative support for the tribunals' judiciary, who hear cases and decide appeals. ${ }^{7}$ In 2010 the Tribunals Service issued a practice direction, the purpose of which was to aid professionals in their report writing, as it was recognised 'that the many demands on professional time made it burdensome to sit down and pull together all the necessary information'. The practice direction aims to help professionals 'by spelling out the minimum requirements and time limits for various types of report'. ${ }^{8}$ It emphasised 
that the requirements, 'have the full force of law and are legally binding. Compliance is compulsory, and not optional. Indeed, when reports are late or fall short of these minimum requirements - with bad consequences for patients, families, carers, doctors, nurses and other professionals - the tribunal has legal power to order remedies, sanctions and costs'. ${ }^{8}$ It gives clear instruction on the requirements of each multidisciplinary report to the tribunal. The instructions for clinician's reports are given in Appendix 1. A review of the literature did not reveal any studies on the quality of medical tribunal reports since the publication in 2010. As far as we are aware, this has never been investigated in a high secure setting. The aim of this survey was therefore to investigate whether medical tribunal reports were meeting the standards as set out in the practice direction issued by the Tribunal Service (2010).

\section{Method}

The objectives were to systematically check the content of medical reports prepared in one high secure hospital in England by marking them all against a checklist of 'acceptable standards'. The total scores reflected how closely the reports adhered to the guidelines. We looked at 50 medical reports, only reports written in 2010 and 2011 were used, i.e. following the publication of the practice direction. Due to limitations of time, the first 50 reports collected were used in the study, although there were more written during this time period. A 13-item checklist was derived from the recommendations as set out in the practice direction for the clinician report (Appendix 2). A proposal was presented to the trust research committee. Ethical approval was not necessary. Once approval was granted, reports were obtained either from the Mental Health Act office or from the electronic shared drive where patient records were stored. Reports were chosen by looking through the alphabetically filed records of patients. Data were collected directly on to an Excel spreadsheet that consisted of 13 items. All results were anonymised and no patient information was used. The names and grades of the authors were recorded confidentially (i.e. whether the report was written by the responsible clinician or by the specialty registrar and countersigned by the responsible clinician).

\section{Results}

Reports were written either by the responsible clinician (34 reports) or by the specialty registrar and countersigned by the responsible clinician (16 reports), and altogether 22 different doctors contributed towards the results (Table 1). Of the reports obtained from the Mental Health Act Office (16 in total), 9 were signed and 7 were not. Of the remaining 34 reports that were obtained from the electronically shared drive, 4 were signed electronically.

There were various ways in which the information on risk (Part b) was presented in reports. Often this information was included as part of a risk assessment (17 reports) and one report included it in the form of the Historical, Clinical and Risk Management Scales (HCR-20)
Table 1 Results of audit of standards of medical tribunal reports

\begin{tabular}{ll} 
& $n(\%)$ \\
\hline General information & $50(100)$ \\
Up to date & $50(100)$ \\
Prepared specifically for tribunal & $44(88)$ \\
Relevant medical history & $50(100)$ \\
Written or countersigned by responsible clinician & \\
\hline Part a & $28(56)$ \\
Mental state & $42(84)$ \\
Treatment for mental disorder & \\
\hline Part b & $35(70)$ \\
Neglected self & $42(84)$ \\
Harm to self & $43(86)$ \\
Harm to others & $42(84)$ \\
Threatened others & $32(64)$ \\
\hline Part c & $17(34)$ \\
Risks if discharged by tribunal & \\
How risks could be managed & $25(50)$ \\
\hline Part d & \\
Patient's strengths/positive factors &
\end{tabular}

violence risk assessment instrument. ${ }^{9}$ Half of the reports included it as a separate statement in the 'Opinions' section at the end of the report. Ten reports (20\%) in total included all of the items on the checklist.

\section{Discussion}

The results show a number of areas where reports are not meeting the minimum standards as set out in the practice direction. For 5 of 13 items in our checklist, less than $80 \%$ of reports evaluated included the required information and are discussed below in more detail.

\section{Mental state}

This was included in only $56 \% \quad(n=28)$ of reports. Assessment of mental state is a core skill of any psychiatrist and failure to include details is inexcusable. Assessment of mental state allows for an appreciation of the current presentation of the patient and is necessary to enable a judgement to be made regarding the presence of and severity of any mental disorder and the risk of harm to self or others. Omitting this acts as a disservice to the tribunal and to our professional and statutory duties as psychiatrists.

\section{Risks if discharged by tribunal and how risks could be managed}

These were included in $64 \%(n=32)$ and $34 \%(n=17)$ of reports respectively and indicate a significant area of poor performance. Given that patients in high security are deemed to pose a grave and immediate risk to the public, it is of paramount importance that this area is given detailed consideration with a robust risk-management package of care offered. It is possible that this area was poorly covered because it is a less common occurrence for patients in high security to be discharged by the tribunal against the advice of the responsible clinician hence responsible clinician's did not prepare for this event in the reports. However, given the 
risks associated with such an eventuality, it is vital that it is considered in tribunal reports together with a view as to how successful these measures might be at preventing risk.

\section{Patient's strengths/positive factors}

This was included in only $50 \%(n=25)$ of reports and is perhaps a reminder that although forensic psychiatry has to consider the worst risks that a patient might pose, we should not fail to consider their strengths. Indeed, this is a central part of the Recovery Agenda. ${ }^{10}$

\section{Neglected self}

This was included in $70 \%(n=35)$ of reports, compared with harm to self, harm to others and threats to others, which were generally better documented. This might be because as forensic psychiatrists we are invariably more preoccupied with documenting risk, often in terms of violence, directed either towards the self or others but it should be remembered that self-neglect also poses great risk to the patient.

\section{Implications}

These failings have important clinical governance implications that need to be addressed. This is necessary not only to ensure the quality of the service being provided but also to avoid potential repercussions by the tribunal. Providing reports for tribunals is an integral part of the role of a psychiatrist. The vital importance of this task and the high stakes associated with it cannot be overstated given the consequences it has for both the liberty of the patient and the protection of the public.

Previous studies have indicated that providing clinicians with a checklist improves the quality of their reports and therefore some consideration should be given to implementing such a measure at a national level. This might be introduced alongside robust performance management of individual clinicians, achieved by evaluating the individual's tribunal reports as part of an appraisal review for example. Certainly this could be included in the review by the responsible officer for revalidation. Alternatively this could be led by the Royal College of Psychiatrists as part of the recertification process. The aim of recertification is to demonstrate that doctors on the specialist register continue to meet the particular standards that apply to their specialty, and writing tribunal reports at an acceptable standard is surely a standard specific to psychiatry.

\section{Recent developments}

Since completion of this study, a second edition of the practice direction ${ }^{11}$ has been issued taking into account key changes that came into effect on 6 April 2012. This made one addition to the instructions for clinicians and this was a statement on 'whether the patient has a learning disability that may adversely affect their understanding or ability to cope with the tribunal hearing, and whether there are any approaches or adjustments that the panel may consider in order to deal with the case fairly and justly." additional piece of information therefore needs to be included in all medical tribunal reports and should be added to the checklist in Appendix 2. It is important that all psychiatrists are aware of this recent update.

\section{Appendix 1}

\section{Clinician's report (p. 14) ${ }^{8}$}

This report must be up-to-date and specifically prepared for the tribunal. Unless it is not reasonably practicable, the report should be written or counter-signed by the patient's Responsible Clinician and must describe the patient's relevant medical history, including:

(a) full details of the patient's mental state, behaviour and treatment for mental disorder;

(b) so far as it is within the knowledge of the person writing the report, a statement as to whether the patient has ever neglected or harmed themselves, or has ever harmed other persons or threatened them with harm, at a time when the patient was mentally disordered, together with details of any neglect, harm or threats of harm;

(c) an assessment of the extent to which the patient or other persons would be likely to be at risk if the patient were to be discharged by the tribunal, and how any such risks could best be managed;

(d) an assessment of the patient's strengths and any other positive factors that the tribunal should be aware of in deciding whether the patient should be discharged.

\section{Appendix 2}

\section{3-item checklist based on the recommendations in the practice direction ${ }^{8}$}

\section{General information}

(1) Up to date

(2) Prepared specifically for tribunal

(3) Relevant medical history

(4) Written or countersigned by responsible clinician

Part a

(5) Mental state

(6) Treatment for mental disorder

Part $b$

(7) Neglected self

(8) Harm to self

(9) Harm to others

(10) Threatened others

Part c

(11) Risks if discharged by tribunal

(12) How risks could be managed

Part d

(13) Patient's strengths/positive factors

\section{About the authors}

Dr Paula Marie Murphy is a specialty registrar (ST6) in forensic psychiatry on the South London and Maudsley rotation. Dr Amlan Basu is a consultant forensic psychiatrist at Broadmoor Hospital in the West London Mental Health Trust. 


\section{References}

1 HM Courts and Tribunal Service. Mental Health Tribunals Guidance. HM Courts and Tribunal Service, no date (http://www.justice.gov.uk/ guidance/courts-and-tribunals/tribunals/mental-health/index.htm).

2 Davison P, Perez de Albeniz P. Reports prepared for the Mental Health Review Tribunals and Managers' Reviews. Psychiatr Bull 1997; 21: 364-6.

3 Ismail K, Smith S, Maden T. Mental health review tribunal medical reports. Psychiatr Bull 1998; 22: 615-8.

4 Regional Chairmen of the Mental Health Review Tribunal for England and Wales Guidance for the Preparation of Medical Reports for the MHRT. Mental Health Review Tribunal Secretariat, 2000.

5 Egleston $\mathrm{P}$, Hunter MD. Improving the quality of medical reports to mental health review tribunals. Psychiatr Bull 2002; 26: 215-8.
6 O'Muirithe B, Shankar R. An audit of the quality of reports to Mental Health Review Tribunals. Med Sci Law 2008; 48: 221-4.

7 HM Courts and Tribunal Service. History of Tribunals Reforms. HM Courts and Tribunal Service, no date (http://www.justice.gov.uk/downloads/ about/hmcts/tribunals/Tribunals-History.pdf).

8 HM Courts and Tribunal Service. Reports for Mental Health Tribunals. Reports Guidance Booklet. Tribunals Service, 2010.

9 Webster CD, Douglas KS, Eaves D, Hart SD. HCR-20: Assessing Risk for Violence (Version 2). Simon Fraser University, 1997.

10 Department of Health. The Journey to Recovery - The Government's Vision for Mental Health Care. Department of Health, 2001.

11 HM Courts and Tribunal Service. Reports for Mental Health Tribunals (2nd edn). Reports Guidance Booklet. Tribunals Service, 2012.

\title{
Audit of monitoring of the parameters of metabolic syndrome in patients on clozapine
}

\author{
John Tully, ${ }^{1}$ Christina Sim, ${ }^{1}$ Razi Hemani, ${ }^{1}$ Malik Munir, ${ }^{1}$ Nasir Khalil, ${ }^{1}$ Sabina Fahy ${ }^{1}$
}

The Psychiatrist (2012), 36, 466-469, doi: 10.1192/pb.bp.111.037994

${ }^{1}$ St Brigid's Hospital, Ballinasloe, Ireland Correspondence to John Tully (john.tully@slam.nhs.uk)

First received 28 Nov 2011, final revision 26 Jul 2012, accepted 13 Aug 2012

\begin{abstract}
Aims and Method High rates of metabolic syndrome exist among patients on clozapine. Monitoring its parameters facilitates interventions which may alleviate negative health consequences. We completed an audit of the monitoring of the parameters of metabolic syndrome in patients on clozapine. The results were compared with the Maudsley Guidelines for monitoring in patients on any antipsychotic medication.
\end{abstract}

Results Initial audit showed high overall rates of concordance with guidelines for the frequency of measurement of blood pressure (91.8\%), but much lower rates for measuring fasting blood glucose (43.2\%) and lipid profile $(52.7 \%)$, and no record of analysis of waist circumference. This prompted development of a formal protocol for measuring parameters. Repeat audit after 1 year showed marked improvement in rates of measurement.

Clinical implications Implementation of relatively straightforward measures, such as the introduction of a one-page form on which to record parameters, can lead to a much improved rate of monitoring for metabolic syndrome. This should in turn prompt therapeutic interventions, which are discussed.

Declaration of interest None.
People with major mental illnesses have an increased prevalence of being overweight and obese, and having hyperglycaemia, dyslipidaemia and hypertension compared with the general population. ${ }^{1}$ These parameters make up the basis of metabolic syndrome as defined by the National Cholesterol Education Programme (NCEP). ${ }^{2}$ Metabolic syndrome in turn predicts development of cardiovascular disease and diabetes. ${ }^{3,4}$ It has been shown that secondgeneration antipsychotics contribute to the development of the syndrome. ${ }^{1,5,6}$ Clozapine is particularly implicated in this regard due to the fact that it has been shown, along with olanzapine, to have the greatest weight gain potential, ${ }^{7}$ and that the risk of diabetes appears to be higher for clozapine than for other second-generation antipsychotics. ${ }^{8}$ One major US study showed a prevalence of metabolic syndrome in patients on clozapine of $53.8 \%$ compared with $20.7 \%$ of those in a comparison group, ${ }^{9}$ while an Irish study showed a comparatively high rate of $46.4 \%$ in its cohort. ${ }^{10}$

Monitoring of the parameters of metabolic syndrome facilitates interventions which may alleviate the negative health consequences of the syndrome. ${ }^{11}$ It has also been shown to be an effective and cost-effective intervention. ${ }^{12}$ 